\title{
How to Explain the Social Skills Development of Pupils?
}

\author{
Agathe Fanchini \\ IREDU-University of Burgundy, France
}

\begin{abstract}
Differences of achievement in school, traditionally studied by researchers in Education, can be analyzed in terms of skills and especially social skills. This scientific field is under construction but social skills are becoming a compulsory notion for actors of the school system and for Educational Sciences. Through a multidisciplinary approach, this article proposes to study the determinants of social skills using social and educational indicators widely borrowed into the explanation of the differences of achievement models, with associated self-image, neuroticism and relationship with school measures. Indeed, these three dimensions are involved in the socialization and development of student skills. A reliable analytic tool of social skills (in a sample of 855 students from 7 to 12 years) enables us to understand for example girls' success at school or the weight of the selfimage in the development of social interpersonal and intra-individual skills. The results which explain determinants of social skills (self-explanatory success) allow opening the debate on the differences in academic achievement in school and redesign the classic pattern of the direct link between the characteristics and achievement, by intermediate effect of social skills.
\end{abstract}

\section{Introduction}

Social skills are an object of research increasingly studied by researchers in Education, particularly by economists. Indeed, many studies demonstrate the effect of these skills on the success of individuals on the labor market in terms of employability or wages [2], [3], [16]. If these social skills have an impact on the careers of individuals, they also play on student achievement: on one hand they are integrated into the French common set of core skills and, on the other hand, research that show the impact of social skills in students' pathways are numerous [3], [14], [15], [20].

As part of a broader research dealing with social skills in the life trajectory of individuals and the particular case of the academic success of students from 7 to 12 years, we will attempt in this paper to understand what are the factors that can explain that some students develop social skills while others do not develop them. In other words, we will try to identify variables that explain the social skills. This approach is part of a broader approach aiming to understand the differences of success.

\section{Context of the research}

According to many authors [16], [18], skill takes action in situation in a given context, functioning as an integrated network. It requires the mobilization of more resources to solve a complex task, either external or, more specifically, internal resources. These internal resources are organized in a trio of knowledge (knowledge, know-how and attitudes). They constitute a system, while being complementary to each other, across the contexts and situations and evolving in the life of the individual. We find among them the theoretical skills, methodological skills and social skills.

Even if there is no consensus on the definition of skill, many researchers still agree on the characteristics we have just mentioned. To define social skills, for which the terms used are various, the approach is similar: it is starting from the characteristics attributed to social skills that can consider their definition [19]. Social skills have the same characteristics as the skills: they are mobilizing more resources (in this case, mainly attitudes) in situations, they are transversal and evolving. They relate to both the self- management (intra-individual) and others management (interpersonal). Social skills are effective and appropriate behaviors and refer to the standards and values of the social group membership of the individual.

In order to operationalize the concept of social skill and according to the theoretical definition that we have given, different inter and intra-individual social skills were selected as part of this research. The choice was based on many researches demonstrating their impact in the trajectory of individuals [4], [5], [14], [15], [16], [20] and each of the 21 skills is part of the classification of the Big Five, widely used by psychologists and economists [16]. Among the interpersonal social skills we find many skills such as sociability, altruism, leadership, listening, politeness, empathy, communication, conflict resolution capacity, cooperation, participation and adaptability. The intra-individual social skills are, in turn, apprehended from the application, perseverance, self-discipline, focus, 
autonomy, curiosity, dynamism, delayed gratification, interest and motivation.

This social skills working definition is accompanied indeed analyzed research showing the impact of social skills in the trajectory of individuals. Now recognized in the labor market, social skills are playing an increasingly important role in the explanation of the success models. That is why we integrate these skills in a broad view of the human capital theory. Moreover, now designated as complementary to cognitive skills [20], social skills contribute to the success of individuals and specifically to academic achievement. Indeed, explaining school failure by the behavior of the student and the family is a field that is considerably growing. In addition, social skills such as perseverance were already cited for their effect on the achievement of academic tasks and their impact on cognitive tasks is now shown [4]. Social skills relating to "role as student" also play on the success [15]: for example, school performance of students are influenced by class participation, cooperation in learning situations, interest in school activities and students' attention in class [1]. These behaviors are valid indicators in predicting future school performance [15]. If the study of social skills in the analysis of differences in school success grows, the analysis of the factors explaining these skills are also involved in the explanation of school failure. The determinants of success, conventionally used by educational researchers, can take the place of explanatory variables in explaining the differences in social skills development models.

Also evaluated in the questionnaire, self-image, neuroticism and report to school, are considered when operationalizing the concept of social skills, such as explanatory factors for the development of these skills. Indeed, several studies show their effect on student achievement.

First, the link between social skills and selfesteem and their effect on the skills called "school" are assumed by many authors. They also states that internalized problems such as anxiety may be related to social skills and self-image of students. Moreover, the correlation between self-image and the success of students is well demonstrated, even if the direction of the relationship can ask questions [6]. A joint development of self-esteem and school performance is also suggested Annie Da-Costa Lasne [9]: "A rewarding self-esteem may bring an increase in its school investment contribute to enhancing aspirations, projects and even their skills and thereby lead to increased academic achievement. " The selfimage can then be viewed as a mediator and intermediate level between skills and academic achievement.

On neuroticism, there are many research demonstrating the negative impact (and long term) of internalized problems on individuals' success [16]. A child with this emotional instability certainly more difficult to develop his skills.

Finally, the report to the school symbolizes the representations that the student has of his school environment. Now a part of socialization in which the individual feels comfortable and confident is beneficial to the creation of conditions conducive to academic success. Research on the academic support in that show improvement compared to the school students, conducive to improving school performance.

We choice to consider self-image, neuroticism and report to school as control variables in the explanatory models of social skills inter and intraindividual. The 21 social skills are therefore added a measure of self-image (self-esteem, self-confidence and locus of control), the neuroticism (anxiety, sadness, shyness) and the report to the school (general report in school, trust and respect for teachers). These three dimensions are complementary to social skills as they allow to understand the behavior and skills of the student as a whole.

\section{Research problem}

Many researches demonstrate the importance of theoretical and methodological skills to explain the success of the pupils or students; but taking an interest in social skills at school allows us to go further in understanding the differences and inequalities of school achievement. Indeed, many studies show the significant weight of social skills on academic, professional and personal individuals' courses. Focusing on social skills is a new way to understand the learning difficulties, different from a mere assessment of knowledge, cognitive skills or classic determinants of academic success. Additionally, evaluating and integrating them into explanatory models of differences in success appears to be a relatively innovative approach to educational research.

\section{Research methodology}

\subsection{Measure tool}

The choice was made on the construction of a questionnaire as an empirical tool. Indeed, the questionnaire survey allows researchers to gather a significant number of data that can be processed statistically. The data collected by questionnaires allow touching a sample of significant size. This collection method also has the advantage of systematic and standardized contract awards which reduce the influence of the investigator and conditions of contracts. The questionnaire submitted to students sample consists of two distinct parts: 
questions relating to the situation of students (social and academic characteristics) and questions assessing their skills and behaviors.

Among the surveyed social characteristics, we chose to interview students about their gender, age, socio- professional category (CPS) of their parents and the size and rank among siblings. Indeed, these variables play on the academic success of students can attest as much research. For example, we can mention for the link between academic achievement and students' gender: Marie Duru-Bellat [11] and Jean-Paul Caille and Fabienne Rosenwald [7]. Research even now show the link between sex and social skills [10]. For the CPS of parents and sibling, research like that of Jean-Paul Caille and Sophie O'Prey [6] or Annie Da-Costa Lasne [9], go in this direction.

The academic data collected are level of education, repetition, the involvement and support of parents for the education of the child. The level of education is a variable strongly correlated with age and often used as well. Repetition and involvement of parents, in turn, are variables that have an impact on student achievement [8], [9], [13].

To ensure the validity and reliability of the questionnaire, each competency, conduct or performance is evaluated with a minimum of 3 items. This procedure allows one hand to limit the problems of understanding and interpretation of questions, two different students can understand differently a question, their response while not referring to the same phenomenon. Asking several questions to measure the same dimension reduces this risk by confirming the answer. Furthermore, the items multiplication procedure limits the random responses of risk as the probability that a student meets at random on several items measuring the same phenomenon is more limited than for a single item. The items that measure the same dimension are distributed and mixed throughout the questionnaire so that students do not spot the link between the items. For example, to assess persistence, the three questions to the questionnaire are inserted: "When I cannot do something, I give up very quickly", "I finished my homework even though I really want to play or do something else" and "When I cannot do something right the first time, I start again". The response formats are offered to students in the form of dichotomous or Likert scale modalities.

Given the age of the respondents, all questions are constructed in first person singular, to allow rapid identification of the pupils. Then, we proposed to the students as much as possible, a scenario the competence or behavior assessed. Finally, concerning the investigation protocol, we ensured all questionnaire administrations, to limit biases of the evaluator and to carry out a standardized approach. All measurements relative to interpersonal social skills and intra-individual, and the other dimensions were built on these principles. This measuring tool enabled subsequently reap a significant number of data that have been subjected to exploratory analyzes to confirm its methodological reliability.

\subsection{Explanatory analyzes}

To determine how variables assessing social skills and other behaviors are structured and associate, a principal components analysis (PCA) was performed on the various dimensions that comprise the self- assessment questionnaire: social skills interpersonal, intra-individual social skills, self-image, neuroticism and report the school.

For inter-individual social skills, the nine factors that arise from the ACP conducted on the 33 items constructed priori refer to sociability, altruism, leadership, politeness, empathy, communication, resolution capability conflict, cooperation and participation. The KMO index (.749) and significance $(\mathrm{p}=.000)$ measuring the quality of inter-item correlations indicate good quality of the analysis. The skill of listening is not found as such but, following analysis and reconsideration of the items that comprise it appear that this skill is found and is redundant with the politeness skills, participation or even empathy. The situation is similar with the adaptability of competence joined, meanwhile, leadership skills, sociability or conflict resolution.

Among the intra-individual social skills (KMO = $.839, \mathrm{p}<.001)$, application, perseverance, selfdiscipline, curiosity, delayed gratification and interest are the seven factors identified by the CPA from the 33 items initially developed. The analysis did not reveal the attention skills, autonomy and dynamism which the items were aggregated by the ACP to other factors. They are indeed particularly integrated with application skills and interest or just define other dimensions as we had not originally envisaged. These new dimensions that appear after the principal component analysis are extrinsic motivation, initiative and fear of punishment. However, in most works dealing motivation is intrinsic motivation that seems beneficial to success: according to the continuum of self-determination, intrinsic motivation (which tends towards selfdetermined behavior) seems more conducive to longterm success. Nevertheless, in the school context, while extrinsic motivation is a form of low selfdetermination related to low school performance, it can be encouraged by teachers. The fear of punishment, in turn, can be a sign of respect for rules and authority: in fact, the child of elementary school age (7 to 12 years), others joined in frame moral development and attempts to comply with social rules.

As for other behaviors assessed in the questionnaire, the CPA first performed on 11 items 
of self-image (4 items for self-esteem and locus of control, 3 items for the confidence) has defined three factors referring to the three initial dimensions $(\mathrm{KMO}=.749, \mathrm{p}<.001)$. The ACP then worked on 10 issues related to neuroticism (anxiety for 4,3 for sadness and shyness) has also identified the same three factors $(\mathrm{KMO}=.749, \mathrm{p}<.001)$. Both components of the report to school are also confirmed by the ACP on 6 items built for this dimension $(\mathrm{KMO}=.749, \mathrm{p}<.001)$. Finally, the measurement tool was subjected to a reliability test measured from a Cronbach's alpha $(\alpha=.839)$ on all items retained after the CPA; Ultimately this comes attest to the internal consistency of items and indicates that the data are satisfactory and can be exploited.

The analyses performed in this work will therefore be from the aggregate score and standardized answers to the various questions associated within a single factor (the response categories were then reassessed on the same scale).

\subsection{Sample description}

The sample consists of 855 students in 16 public schools in the same town. It is distributed equitably between girls and boys (48.2\% of girls and 51.2\% boys) and then seems representative of the reference population counts $48.9 \%$ of girls enrolled in primary education (French population). The average age of 9.24 years $($ median $=9, \mathrm{SD}=1.01, \min =7, \max =$ 12) and the most represented age are 8 years (23.7\%), 9 years $(27.1 \%)$ and $10(37.4 \%)$, which corresponds to the three education levels of the sample pupils.

Regarding the occupational status of parents, the most represented categories in mothers are inactive mothers (18.9\%), employed (39.2\%) and intermediate profession $(15.4 \%)$, while in fathers, it is the workers (28.9\%), employees (20.8\%) and managers (11.7\%). Compared to the French population, mothers and fathers in our sample in a profession of the category of employees, are overrepresented. We can also see that the mothers in our sample are more unemployed than in the population, while fathers are less represented than in the total population. Moreover, we can highlight the very small number of retired in our sample, which is due to the considerable difference between the average age of the first child for women (28 years and 30 years, regardless of whether the row sibling) and the average age of retirement (around 61 years). This under-representation of retired in part that the category of employees in our sample is overrepresented. Finally, other professional categories are fairly representative of the French population.
As to family composition, sample students are part of a family with two children $32.7 \%$ of them and $27.5 \%$ for three children. Regarding the rank among siblings, $30.3 \%$ are juniors, cadets $29.6 \%, 27.5 \%$ and $11.5 \%$ of only children.

For academic delay, $11.1 \%$ of students in our sample have already repeated during their past schooling. This figure is remarkably higher than the average rate of $1 \%$ repetition within the reference population. Finally, according to the statements of students, $78.1 \%$ of parents seem to be involved in their children's schooling.

\section{Results}

The results presented here are structured in two stages: first, the educational attainment of the students related to their social skills "level" will be exposed. Then, the effect of various determinants of social skills will be analyzed.

\subsection{The academic level of the students and their social skills}

Understanding how social skills are built and what are the determinants that can explain their development, contributes to the understanding of differences of success. The following table summarizes the distribution of students according to their academic performance judged by teachers at the beginning of the school year, and their "level" of competence.

The pivot table summarizes the distribution of skills depending on the level of the student judged by the teacher early in the year and the significance of the difference, indicated in the last column was analyzed using Fisher's test accompanies Chi-2 test. The results indicate that among the students who master the different social skills and other behaviors, by the majority of students are considered "good" by their teacher at the beginning of the school year. For example, significant differences between the polite students: they are $14 \%$ to be weak students, $33.8 \%$ of average students and over half good students. This trend also emerged for other social skills inter and intra-individual.

The value of these results is multiple. First, they confirm the need to understand the mechanisms and determinants involved in the development of social skills that seem related to students' grade level. Then, these descriptive results support the hypothesis that good students develop social skills and adopt effective and appropriate behaviors. Finally, with this assessment (low, medium, high) based on the perception of the teacher, we can assume that what is assessed by reference to the overall perception of the student and of his role as students: teachers perceive 
Table 1. Distribution of skills and behaviours on the perception of grade level by the teacher at the beginning of the school year

\begin{tabular}{|c|c|c|c|c|}
\hline & \multicolumn{4}{|c|}{ Perception grade level by the teacher } \\
\hline & low & middle & high & sign. \\
\hline \multicolumn{5}{|c|}{ Interpersonal social skills } \\
\hline Conflict resolution capacity & $15 \%$ & $35 \%$ & $50 \%$ & $* *$ \\
\hline Empathy & $16,3 \%$ & $34,6 \%$ & $49 \%$ & $*$ \\
\hline Politeness & $14 \%$ & $33,8 \%$ & $52,3 \%$ & $* * *$ \\
\hline Participation & $16 \%$ & $32,2 \%$ & $51,9 \%$ & $* *$ \\
\hline Cooperation & $19,4 \%$ & $34,7 \%$ & $45,9 \%$ & $* * *$ \\
\hline Leadership & $18,2 \%$ & $35,4 \%$ & $46,4 \%$ & ns \\
\hline Altruism & $19,2 \%$ & $34,7 \%$ & $46,1 \%$ & $\mathrm{~ns}$ \\
\hline Sociability & $17,4 \%$ & $36,2 \%$ & $46,4 \%$ & ns \\
\hline Communication & $18,3 \%$ & $32,9 \%$ & $48,8 \%$ & ns \\
\hline \multicolumn{5}{|c|}{ Intra-personal social skills } \\
\hline Application & $14,2 \%$ & $32,8 \%$ & $53 \%$ & $* * *$ \\
\hline Interest & $17,1 \%$ & $34,1 \%$ & $48,8 \%$ & ns \\
\hline Curiosity & $17,1 \%$ & $33,2 \%$ & $49,7 \%$ & $* *$ \\
\hline Perseverance & $15,4 \%$ & $34,6 \%$ & $50 \%$ & $* * *$ \\
\hline Extrinsic motivation & $21,9 \%$ & $25 \%$ & $53,1 \%$ & ns \\
\hline Self-discipline & $17,5 \%$ & $35,1 \%$ & $47,4 \%$ & $\mathrm{~ns}$ \\
\hline Delayed gratification & $15,3 \%$ & $35,6 \%$ & $49,2 \%$ & $* *$ \\
\hline Initiative & $14,5 \%$ & $30,6 \%$ & $54,8 \%$ & $\mathrm{~ns}$ \\
\hline Fear of punishment & $17,5 \%$ & $34,7 \%$ & $47,8 \%$ & $\mathrm{~ns}$ \\
\hline
\end{tabular}

certainly differences in terms of social skills among their students.

Now analyze the factors that explain why some students develop or not the various social skills and other behaviors.

\subsection{The determinants of social skills}

The effects of the social characteristics of the students and school social skills were calculated from mean comparisons (ANOVA) and simple linear regression. Comparing averages in the analysis allows to consider the significance of difference between groups of independent variable in relation to the dependent variable. The univariate or simple linear regression, meanwhile, is used to analyze the function that relates a dependent variable and one dependent variable.

This type of model is used in an exploratory approach because even if it avoids all the problems 
of collinearity, as the explanatory factor is unique, there is no evidence that the effect of the independent variable on the dependent variable. Standardized scores of skills and behaviors take the place of the dependent variable and the characteristics of students in independent variable.

For social characteristics, a kind of effect can be observed. Indeed, most girls develop conflict resolution skills, empathy, politeness, altruism, sociability, application, extrinsic motivation, selfdiscipline and initiative. Moreover, they tend to be more anxious and sadder than boys. However, compared to girls, boys develop more leadership skills, curiosity and delayed gratification. However, a clear advantage in favour of girls seems to be emerging through these results. Indeed, they are particularly useful for understanding why girls do better at school than boys as Georges Felouzis [12] had already demonstrated, the girls have a report to school more favourable than boys and adopt more consistent behavior of the institution. In our research, behaviors already reported as important to the success of Felouzis are translating social skills especially during the child socialization process. According to our analysis, the girls have mastered the "role as student" and social skills conducive to success than boys, which results also go in the direction of the work of Marie Duru Bellat [11].

On the side of the age of pupils, a negative effect appears in the analyses: youngest seem to master more skills than other older students sample. The younger students seem more relevant than others. These results may be subject to several interpretations: either young students adopt more conducive to successful behavior or they are more strongly subject to social desirability bias. Indeed, we know that most students are young, the more they tend to evaluate themselves positively.

Concerning the parents, analyzes show first of all that the PCS of the mother doesn't play on social skills of students. Father's CPS significant results are more numerous than for the mother: for example, children whose father is absent, are less polite, participate less in class, are less diligent, curious and persistent.

For most findings on family size, the results are positive for students from families with two children: it is demonstrated that they indeed do better in school than other [7]. The rank among siblings, meanwhile, plays very few on social skills.

For school characteristics, a negative effect of repetition is showed on social skills interpersonal (conflict resolution, empathy, politeness, participation, communication) and intra-individual (application, interest, curiosity, perseverance, extrinsic motivation, delayed gratification, fear punishment). Further analyzes indicate that repeaters also have a negative self-image and are more anxious and sad more developed than students on time. Also, there fear the punishment are more developed than others. These results quite eloquent on repetition: they evoke the research that indicates that this repetition is against-productive and negative for the students. They do not perform better, have a negative self-image and show more sadness and anxiety that students "on time".

Finally, there is a significant relationship between parental involvement and the development of social skills. The direction of the relationship between the two variables is also almost unequivocal: there is a positive effect of parental involvement in children's education on the development of social skills evaluated. The positive effect is found for the conflict resolution, empathy, politeness, participation, cooperation, altruism, sociability, communication, application, interest, curiosity, selfdiscipline, and the spirit of initiative. These results demonstrate an effect of parental involvement in schooling but not only on specific skills as students (such as participation, interest, self-discipline, curiosity or the spirit of initiative). Other social skills like empathy and communication are positively influenced by this parental involvement. Involvement in education is, indeed, one of the elements that characterize parenting [9]: it is also a sign of parenting certainly "structuring" (not loose) [13]. Family and parenting involve in child socialization in which social skills develop.

However, parental education seems to vary according to the socioeconomic background of families [13]. We tested the link between parental involvement and CPS: Chi2 results between the variable "CPS father" and "parent involvement" variable is not significant while the CPS's father played on the success and the development of social skills. However, there is a significant link between CPS mother and involvement in schooling ( $\mathrm{p}=$ .018 ), referring to the "omnipresence of the mother" in supporting schooling. Recall that we measure the involvement in schooling, not the child-raising style or educational practices.

By analyzing in detail the relationship between involvement in schooling and the CPS of the mother, the only significant result is a negative impact of the situation "unemployed" on the implication: inactive mothers (in the most cases, a disadvantaged background) are less likely to get involved in the education of their children than others. Although some research shows some parental authority centred on surveillance and punishment in the said areas "popular", it is complex to generalize the results to a whole class. However, to clarify these results, we would have to collect the educational level of the parents or the cultural practices of families [13]. 


\subsection{Final results}

The latest analyzes calculate the combined effect of social and academic characteristics and selfimage, the neuroticism and the report to the school social skills assessed in this research. It is understood that the most explanatory variables are sex, father's CPS, education level (which can be considered age), repetition, and parental involvement.

To address our hypothesis that self-image, neuroticism and report to school may explain the fact to master social skills or not, we have test multiple regressions. Introduced to models, scores of selfimage, neuroticism and report to school are significantly increase the proportion of variance explained, indicating a significant effect of these behaviors in explaining differences in social skills mastery. In more details, we can see that the selfimage and the report to the school explaining social skills scores inter and intra-individual, while between neuroticism into account only in explaining the differences in social interpersonal skills. When the self-image, neuroticism and report to school are introduced to explain the social skills models, these explanatory variables lose weight. This can certainly be explained by the existence of an effect of gender and academic variables directly on these behaviors. The meaning of the coefficients, meanwhile, says that if the self-image and the relationship to school have a positive effect on the development of social skills, neuroticism has a negative effect. That means students with a positive self-image, feeling good about their school environment and demonstrating emotional stability (not neuroticism), tend to better develop their social skills inter and intra-individual.

\section{Discussion}

Even if the general framework of this research contribute to explain the differences of success in elementary school, some problems inherent in educational research remain. The problem of measuring success remains complex and an assessment of the theoretical and methodological skills, with national assessments, for example, would be more reliable indicators of purely academic success of students. The self-assessment of skills also creates certain limitations. To avoid bias due to the subjectivity of respondents, it would be possible to establish a $360^{\circ}$ protocol, that is to say a questionnaire to all the players who surround the individual in his social environment. Finally, the analyzes could enable to understand how to structure social skills and if, as the theoretical and methodological skills, there is a pyramidal structure [18] within the dynamic system of social skills.

\section{Conclusion}

The analyses conducted for this research indicate first, that there is a link between the perception of grade by the teacher and the level of social skills of students. These preliminary results confirm in a sense the hypothesis that social skills are involved in explaining differences in educational pathways. In addition, these social skills can be explained by individual characteristics such as gender, income participating in explaining the success of girls in school. Parental involvement has a positive and significant gross effect on social skills that seem to grow in part by family socialization.

However, if it is impossible institutionally and pedagogically to have an effect on student characteristics; but self-image, neuroticism and relationship with school may evolve and be educated as well as the skills which, by definition, are developed throughout life [17], [20].

\section{References}

[1] K. R Alexander, "First grade classroom behavior: its short and long-term consequences for school performance", Child Development, 64, 1993, pp. 801-814.

[2] Almlund M., Duckworth A. L., Heckman J. J., and Kautz T., Personality Psychology and Economics. University of Chicago, 2011.

[3] L. Borghans, J. J. Heckman and B. Ter Weel, "The Economics and Psychology of Personality Traits", Journal of Human Resources, 43(4), 2008, pp. 9721059.

[4] Borghans L., Meijers H., and Ter Weel B., The Role of Noncognitive Skills in Explaining Cognitive Test Scores, IZA Discussion paper series No. 2429, Institute for the Study of Labor (IZA), Bonn, 2006.

[5] S. Bowles, H. Gintis, and M. Osborne, "The Determinants of Earnings: A Behavioral Approach", Journal of Economic Literature, 39, 2001, pp. 11371176.

[6] J.-P. Caille and S. O'Prey, " Estime de soi et réussite scolaire sept ans après l'entrée en sixième », Éducation et formations, 72, 2005, pp. 2552.

[7] Caille J.-P. and Rosenwald F., Les inégalités de réussite à l'école élémentaire: construction et évolution (Portait Social), INSEE, France, 2006.

[8] O. Cosnefroy and T. Rocher, « Le redoublement au cours de la scolarité obligatoire: nouvelles analyses, mêmes constats », Éducation et formations, 70, 2004, pp. 7382 .

[9] Da-Costa Lasne, A., La singulière réussite scolaire des enfants d'enseignants: des pratiques éducatives parentales spécifiques?, PhD in Education, University of Burgundy, Dijon, 2012. 
[10] T. A. DiPrete and J. L. Jennings, "Social and behavioral skills and the gender gap in early educational achievement", Social Science Research, 41(1), 2012, pp. 1 15.

[11] M. Duru-Bellat, " La (re)production des rapports sociaux de sexe : quelle place pour l'institution scolaire? » Travail, genre et sociétés, 19(1), 2008, pp. 131149.

[12] G. Felouzis (1990). Filles et garçons au collège: comportements, dispositions et réussite scolaire en sixième et cinquième, thèse de doctorat, University of AixMarseille 1.

[13] A. Feyfant, « Les effets de l'éducation familiale sur la réussite scolaire », Veille et Analyses - ifÉ, 63, 2011, 14 p.

[14] B. Gendron « Capital émotionnel fille-garçons: quelles différences à l'école », In Carrières scolaires Symposium Genre et Education. Strasbourg. 2007.

[15] P. Guimard, Cosnefroy, O. and A. Florin, « Évaluation des comportements et des compétences scolaires par les enseignants et prédiction des performances et des parcours à l'école élémentaire et au collège ", L'orientation scolaire et professionnelle, 36(2), 2007, pp. 179202.

[16] J. J. Heckman and T. Kautz, "Hard Evidence on Soft Skills", Labour Economics, 19(4), 2012, pp. 451464.

[17] Heckman J. and Kautz T. Fostering and Measuring Skills: Interventions That Improve Character and Cognition, Working Paper No. 19656, National Bureau of Economic Research, Cambridge, MA, 2013.

[18] Morlaix S., Compétences des élèves et dynamique des apprentissages, Presses universitaires de Rennes, Rennes, 2009.

[19] Nangle D. W., Hansen D. J., Erdley C. A., and Norton, P. J., (2010). Practitioner's guide to empirically based measures of social skills. Springer, New York, 2010.

[20] OECD, Skills for Social Progress: The power of Social and Emotional Skills OECD Skills Studies, Paris, 2015. 